\title{
Effect of propofol, midazolam and dexmedetomidine on ICU patients with sepsis and on arterial blood gas
}

\author{
JIA DING $^{1 *}$, YUWEN CHEN $^{2 *}$ and YUAN GAO ${ }^{1}$ \\ Departments of ${ }^{1}$ Intensive Care Unit and ${ }^{2}$ Anesthesiology, \\ Renji Hospital, School of Medicine, Shanghai Jiaotong University, Shanghai 200127, P.R. China
}

Received May 15, 2019; Accepted July 25, 2019

DOI: $10.3892 /$ etm.2019.8091

\begin{abstract}
Effects of propofol, midazolam and dexmedetomidine on patients with sepsis in intensive care unit (ICU) and on arterial blood gas (ABG) were studied. In total 429 ICU patients with sepsis, admitted to Renji Hospital, School of Medicine, Shanghai Jiaotong University from May 2015 to January 2019, were selected as research subjects for a prospective analysis. All patients received basic treatment, such as anti-infection treatment, correction of shock and improvement of microcirculation. One hundred and fifty-two patients who were treated with propofol for sedation served as group A, 146 patients who were treated with midazolam for sedation served as group B, and 131 patients who were treated with dexmedetomidine for sedation served as group $\mathrm{C}$. The three groups of patients were compared in terms of diastolic blood pressure (DBP), systolic blood pressure (SBP), heart rate (HR), arterial partial pressure of oxygen $\left(\mathrm{PaO}_{2}\right)$, arterial partial pressure of carbon dioxide $\left(\mathrm{PaCO}_{2}\right)$, cardiac troponin $\mathrm{T}$ (cTnT) and creatine kinase-MB (CK-MB) before and after treatment. APACHE II score was used to evaluate the sedative effects. The wake-up time of the patients, the length of ICU stay and the adverse reactions were recorded. There was no significant difference among groups $\mathrm{A}, \mathrm{B}$ and $\mathrm{C}$ in terms of HR, SBP, DBP, $\mathrm{PaO}_{2}, \mathrm{PaCO}_{2}, \mathrm{cTnT}, \mathrm{CK}-\mathrm{MB}$ and APACHE II score before treatment, and SBP, DBP, cTnT and HR after treatment $(P>0.050)$. After treatment, there was no significant difference between groups $\mathrm{A}$ and $\mathrm{B}$ with respect to $\mathrm{CK}-\mathrm{MB}$ and APACHE II score $(\mathrm{P}>0.050)$. The wake-up time in group A was significantly longer than that in groups $\mathrm{B}$ and $\mathrm{C}(\mathrm{P}<0.001)$. In conclusion, propofol, midazolam and dexmedetomidine are
\end{abstract}

Correspondence to: Dr Yuan Gao, Department of Intensive Care Unit, Renji Hospital, School of Medicine, Shanghai Jiaotong University, 1630 Dongfang Road, Pudong New Area, Shanghai 200127, P.R. China

E-mail: gtcq76@163.com

*Contributed equally

Key words: propofol, midazolam, dexmedetomidine, sepsis, intensive care unit effective and safe in the sedative treatment of ICU patients with sepsis, but dexmedetomidine has the best effect on protecting blood pressure and cardiac functions, which is worthy of use in the clinic.

\section{Introduction}

Sepsis is a systemic inflammatory response syndrome caused by infection, and it has been proven that there are bacteria or highly suspicious focus of infection in patients' blood (1). Currently, the incidence of sepsis is extremely high worldwide and, according to statistics, there are 270 patients with the disease per 100,000 people (2). Moreover, the incidence is increasing year by year (3). Sepsis is dangerous and has a very high fatality rate, with a mortality of $15.00 \%$ (4). Due to its high incidence and mortality, more effective diagnosis and treatment schemes for the disease have been explored (5-7). With the deepening of research and the development of medical technology in recent years, remarkable progress has been made in anti-infection treatment and organ support therapy, but the fatality rate of sepsis remains high (8). Therefore, the effective treatment of sepsis is still a major research difficulty.

At present, sepsis is mostly common in intensive care unit (ICU) and usually complicated with organ dysfunction, so the treatment of the disease is difficult (9). ICU patients with sepsis are clinically treated by sedative treatment, because of the great discomfort and pain caused by invasive operation for ICU patients (10). Studies have shown that traditional anesthetics propofol, midazolam and dexmedetomidine have strong sedative, analgesic and certain anti-inflammatory effects on ICU patients with sepsis, and they can relieve the anxiety and discomfort of the patients $(11,12)$. According to Fernando et al (13), propofol has a better anti-inflammatory effect on rats with pneumonia. Yamamura et al (14) have reported that midazolam and dexmedetomidine have high safety during mechanical ventilation of patients with sepsis. Studies worldwide are usually limited to the sedative treatment with anesthetics, and which drug is the most suitable for ICU patients with sepsis remains controversial. Therefore, the effects of propofol, midazolam and dexmedetomidine on the sedative treatment of ICU patients with sepsis and on arterial blood gas $(\mathrm{ABG})$ were analyzed in this study, in order to determine the most suitable drug for the sedative treatment and provide reliable guidance for clinical practice. 
Table I. Comparison of general information [n (\%)].

\begin{tabular}{|c|c|c|c|c|c|}
\hline Factor & Group A $(n=152)$ & Group B $(n=146)$ & Group C $(n=131)$ & $\chi^{2}$ or $\mathrm{F}$ value & P-value \\
\hline Age (years) & $55.27 \pm 11.26$ & $54.98 \pm 11.57$ & $55.09 \pm 10.84$ & 0.025 & 0.975 \\
\hline $\mathrm{BMI}\left(\mathrm{kg} / \mathrm{cm}^{2}\right)$ & $21.87 \pm 5.37$ & $21.26 \pm 5.08$ & $22.05 \pm 5.86$ & 0.824 & 0.440 \\
\hline WBC (x1099/1) & $9.24 \pm 2.85$ & $9.63 \pm 3.04$ & $9.55 \pm 2.77$ & 0.754 & 0.471 \\
\hline $\mathrm{RBC}\left(\mathrm{x} 10^{12} / \mathrm{l}\right)$ & $5.83 \pm 1.26$ & $5.98 \pm 1.53$ & $5.77 \pm 1.30$ & 0.879 & 0.416 \\
\hline PLT (x109/1) & $284.62 \pm 36.24$ & $278.66 \pm 35.25$ & $280.69 \pm 31.09$ & 1.157 & 0.316 \\
\hline Sex & & & & 0.846 & 0.655 \\
\hline Male & $110(72.37)$ & $101(69.18)$ & $97(74.05)$ & & \\
\hline Female & $42(27.63)$ & $45(30.82)$ & $34(25.95)$ & & \\
\hline Place of residence & & & & 0.891 & 0.640 \\
\hline City & $127(83.55)$ & $116(79.45)$ & $108(82.44)$ & & \\
\hline Countryside & $25(16.45)$ & $30(20.55)$ & $23(17.56)$ & & \\
\hline \multicolumn{6}{|l|}{ Ethnicity } \\
\hline Han & $144(94.74)$ & $136(93.15)$ & $126(96.18)$ & & \\
\hline Minority & $8(5.26)$ & $10(6.85)$ & $5(3.82)$ & & \\
\hline Combined diseases & & & & 2.141 & 0.995 \\
\hline Tumor & $74(48.68)$ & $66(45.21)$ & $65(49.62)$ & & \\
\hline Severe pneumonia & $32(21.05)$ & $27(18.49)$ & $26(19.85)$ & & \\
\hline Severe trauma & $15(9.87)$ & $16(10.96)$ & $12(9.16)$ & & \\
\hline Severe cholangitis & $12(7.89)$ & $15(10.27)$ & $11(8.40)$ & & \\
\hline Severe pancreatitis & $8(5.26)$ & $10(6.85)$ & $9(6.87)$ & & \\
\hline Diffuse peritonitis & $11(7.24)$ & $12(8.22)$ & $8(6.11)$ & & \\
\hline Surgery & & & & 0.597 & 0.742 \\
\hline Yes & $75(49.34)$ & $69(47.26)$ & $68(51.91)$ & & \\
\hline No & $77(50.66)$ & 77 (52.74) & 63 (48.09) & & \\
\hline Chemotherapy & & & & 0.523 & 0.770 \\
\hline Yes & 34 (22.37) & 29 (19.86) & 25 (19.08) & & \\
\hline No & $118(77.63)$ & $117(80.14)$ & $106(80.92)$ & & \\
\hline
\end{tabular}

BMI, body mass index; WBC, white blood cells; RBC, red blood cells; PLT, platelet.

\section{Patients and methods}

General information. In total 429 ICU patients with sepsis, admitted to Renji Hospital, School of Medicine, Shanghai Jiaotong University (Shanghai, China) from May 2015 to January 2019, were selected as research subjects for a prospective analysis. There were 308 males and 121 females, 43-76 years of age with an average age of 56.15 \pm 10.84 years. The study was approved by the Ethics Committee of Renji Hospital, School of Medicine, Shanghai Jiaotong University. Patients who participated in this research had complete clinical data and signed informed consents were obtained from the patients or their guardians. Inclusion criteria: patients who met the diagnostic criteria for sepsis (15); patients who needed sedative treatment; patients who had complete medical records; patients who had good compliableness; patients with complete medical records; patients who cooperated with the arrangement of the medical staff in this hospital; and ICU patients. Exclusion criteria: pregnant women; patients who were allergic to drugs; patients with heart failure ( $\geq$ grade III); patients with renal failure (Rifle criteria $\geq F$ ); patients with hepatic failure (total plasma protein, $<30 \mathrm{~g} / \mathrm{l}$; bilirubin, $>85 \mathrm{~mol} / \mathrm{l}$ ); patients with brain death; patients who were transferred to another hospital; patients who were bedridden for a long time; patients with mental illness; or patients with physical disability.

Methods. All patients received basic treatment, such as, anti-infection treatment, correction of shock and improvement of microcirculation. On this basis, 152 patients who were treated with propofol (Aspen Pharmacare; $1 \% \mathrm{w} / \mathrm{v}$ ) for sedation served as group A, 146 patients who were treated with midazolam (Jiangsu Nhwa Pharmaceutical Co.,Ltd.; SFDA approval no. H10980025) for sedation served as group B, and 131 patients who were treated with dexmedetomidine (Jiangsu Hengrui Medicine Co., Ltd.; SFDA approval no. H20090248) for sedation served as group C. Patients in group A were continuously pumped with propofol using a micro pump at $0.05 \mathrm{mg} / \mathrm{kg} / \mathrm{min}$ for analgesia, during which the patients were intravenously injected with propofol with a loading dose of $1-3 \mathrm{mg} / \mathrm{kg}$ for $30-60 \mathrm{sec}$. After that, the patients were continuously pumped with propofol using the 


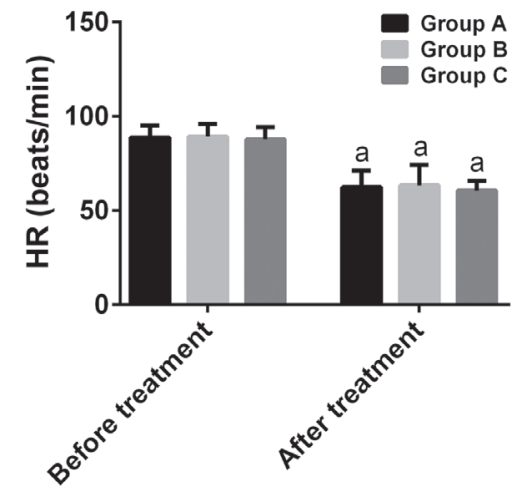

Figure 1. Comparison of HR before and after treatment. There was no significant difference among groups A, B and C in HR before or after treatment. After treatment, HR in the three groups was significantly lower than that before treatment. ${ }^{\mathrm{a}} \mathrm{P}<0.001$, compared with $\mathrm{HR}$ in the same group before treatment. HR, heart rate.

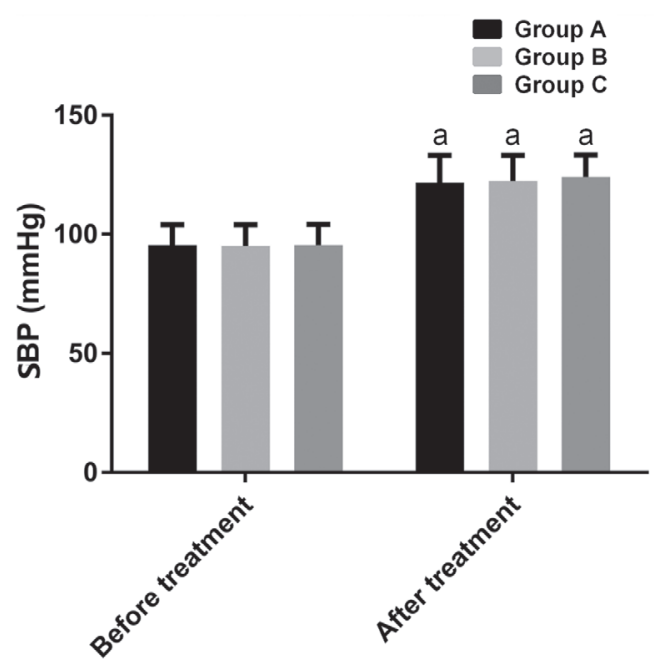

Figure 2. Comparison of SBP before and after treatment. There was no significant difference among groups A, B and C in SBP before or after treatment. After treatment, SBP in the three groups was significantly higher than that before treatment. ${ }^{a} \mathrm{P}<0.001$, compared with SBP in the same group before treatment. SBP, systolic blood pressure.

micro pump and the dosage of medication was $0.5-4 \mathrm{mg} / \mathrm{kg} / \mathrm{h}$. Analgesic treatment for patients in group B was the same as for group A. After that, the patients were continuously pumped with midazolam using the micro pump at $0.05 \mathrm{mg} / \mathrm{kg} / \mathrm{h}$ with a speed of $1 \mathrm{ml} / \mathrm{h}$. Analgesic treatment for patients in group $\mathrm{C}$ was the same as for group A. After that, the patients were intravenously pumped with dexmedetomidine with a loading dose of $1 \mu \mathrm{g} / \mathrm{kg} / \mathrm{h}$ for $10 \mathrm{~min}$, and then continuous intravenous pumping of dexmedetomidine for sedative treatment was carried out at 0.2-0.7 $\mu \mathrm{g} / \mathrm{kg} / \mathrm{h}$. Diastolic blood pressure (DBP), systolic blood pressure (SBP) and heart rate (HR) were recorded before and after treatment in all three groups. Arterial blood was extracted before and after treatment from the patients of the three groups for blood gas analysis. Venous blood was also extracted from the patients of the three groups, before and after treatment, to detect cardiac troponin $\mathrm{T}$ (cTnT) and creatine kinase-MB (CK-MB).

Observation indexes. For blood pressure function, DBP, SBP and HR were recorded before and after treatment; for blood

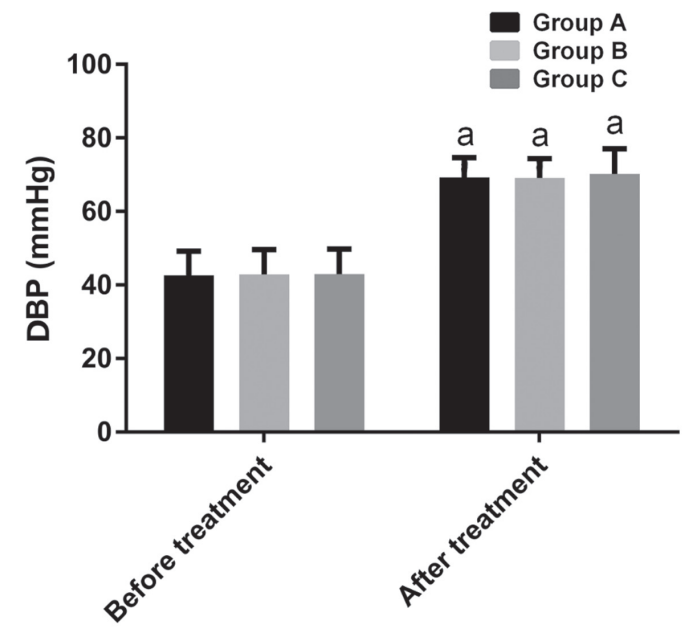

Figure 3. Comparison of DBP before and after treatment. There was no significant difference among groups A, B and C in DBP before or after treatment. After treatment, DBP in the three groups was significantly higher than that before treatment. ${ }^{\mathrm{a}} \mathrm{P}<0.001$, compared with $\mathrm{DBP}$ in the same group before treatment. DBP, diastolic blood pressure.

gas function, the arterial partial pressure of oxygen $\left(\mathrm{PaO}_{2}\right)$ and arterial partial pressure of carbon dioxide $\left(\mathrm{PaCO}_{2}\right)$ were recorded before and after treatment; for cardiac function, cTnT and CK-MB were recorded before and after treatment; the sedative effect was evaluated using APACHE II score (16); the wake-up time, the length of ICU stay, and the adverse reactions during the sedative treatment were recorded. Incidence of adverse reactions $=$ (number of adverse reactions) $/($ total number) $\mathrm{x} 100 \%$

Statistical analysis. SPSS 24.0 (Beijing Strong-Vinda Information Technology Co., Ltd.) was used to statistically analyze the experimental results, and GraphPad 8 (Softhead Inc.) to plot the figures and check the results. Count data, such as sex, were expressed as rate and Chi-square test was used for their comparison within groups. Measurement data, such as DBP and SBP, were expressed as the mean \pm standard deviation and t-test was used for their comparison within groups. One-way analysis of variance and LSD post hoc test were used for comparisons between multiple groups. $\mathrm{P}<0.050$, was considered to indicate a statistically significant difference.

\section{Results}

Comparison of general information. There was no significant difference among groups $\mathrm{A}, \mathrm{B}$ and $\mathrm{C}$ in age, body mass index (BMI), white blood cells (WBC), red blood cells (RBC), platelet (PLT), sex, place of residence, ethnicity, combined diseases, surgery and chemotherapy $(\mathrm{P}>0.050)$, indicating that the three groups of patients were comparable (Table I).

Comparison of blood pressure function. There was no significant difference among groups A, B and C in HR, SBP and DBP before or after treatment $(\mathrm{P}>0.050)$. After treatment, DBP and SBP in the three groups were significantly higher than those before treatment $(\mathrm{P}<0.001)$; HR in the three groups after treatment was significantly lower than that before treatment $(\mathrm{P}<0.001)$ (Figs. 1-3). 
Table II. Comparison of blood gas function.

\begin{tabular}{|c|c|c|c|c|c|}
\hline Blood gas & Group A $(n=152)$ & Group B $(n=146)$ & Group $C(n=131)$ & $F$ value & P-value \\
\hline \multicolumn{6}{|l|}{$\mathrm{PaO}_{2}(\mathrm{mmHg})$} \\
\hline Before treatment & $75.23 \pm 6.84$ & $76.18 \pm 7.05$ & $74.39 \pm 6.97$ & 2.300 & 0.102 \\
\hline After treatment & $76.52 \pm 6.79$ & $75.18 \pm 6.84$ & $75.33 \pm 7.14$ & 1.669 & 0.190 \\
\hline \multicolumn{6}{|l|}{$\mathrm{PaCO}_{2}(\mathrm{mmHg})$} \\
\hline Before treatment & $38.94 \pm 6.85$ & $39.14 \pm 7.04$ & $39.20 \pm 6.90$ & 1.368 & 0.256 \\
\hline After treatment & $39.08 \pm 6.54$ & $38.68 \pm 6.97$ & $37.84 \pm 7.10$ & 1.180 & 0.308 \\
\hline
\end{tabular}

$\mathrm{PaO}_{2}$, arterial partial pressure of oxygen; $\mathrm{PaCO}_{2}$, arterial partial pressure of carbon dioxide.

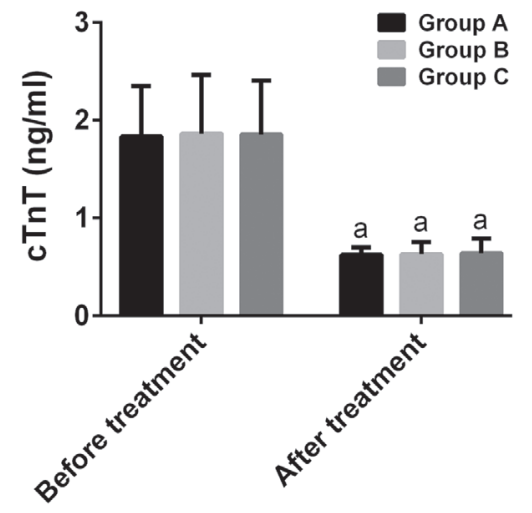

Figure 4. Comparison of cTnT before and after treatment. There was no significant difference among groups A, B and C in cTnT before or after treatment. After treatment, cTnT in the three groups was significantly lower than that before treatment. ${ }^{a} \mathrm{P}<0.001$, compared with $\mathrm{cTnT}$ in the same group before treatment. cTnT, cardiac troponin T.

Comparison of blood gas function. Among groups A, B and C there was no significant difference in $\mathrm{PaO}_{2}$ and $\mathrm{PaCO}_{2}$ before or after treatment $(\mathrm{P}>0.050)$. Also, there was no significant difference before and after treatment in the three groups in terms of $\mathrm{PaO}_{2}$ or $\mathrm{PaCO}_{2}(\mathrm{P}>0.050$; Table II $)$.

Comparison of cardiac function. There was no significant difference among groups $\mathrm{A}, \mathrm{B}$ and $\mathrm{C}$ in cTnT and CK-MB before treatment, as well as cTnT after treatment $(\mathrm{P}>0.050)$. After treatment, cTnT and CK-MB in group A were $0.62 \pm 0.08$ and $2.68 \pm 0.88 \mathrm{ng} / \mathrm{ml}$, respectively, in group B were $0.63 \pm 0.12$ and $2.63 \pm 0.84 \mathrm{ng} / \mathrm{ml}$, respectively, and in group $\mathrm{C}$ were $0.64 \pm 0.15$ and $2.16 \pm 0.44 \mathrm{ng} / \mathrm{ml}$, respectively. After treatment, cTnT and CK-MB in the three groups were significantly lower than those before treatment $(\mathrm{P}<0.001)$, and there was a statistically significant difference among the three groups in CK-MB $(\mathrm{P}<0.001)$. After treatment, there was no statistically significant difference between groups $\mathrm{A}$ and $\mathrm{B}$ in CK-MB $(\mathrm{P}>0.050)$, while in group $\mathrm{C}$ the value of $\mathrm{CK}-\mathrm{MB}$ was significantly lower than that in groups $\mathrm{A}$ and $\mathrm{B}(\mathrm{P}<0.001)$ (Figs. 4 and 5).

Comparison of sedative effects. There was no significant difference among groups $\mathrm{A}, \mathrm{B}$ and $\mathrm{C}$ in APACHE II score before treatment and length of ICU stay $(\mathrm{P}>0.050)$, whereas after treatment, there were statistically significant differences among the three groups in the wake-up time and APACHE II

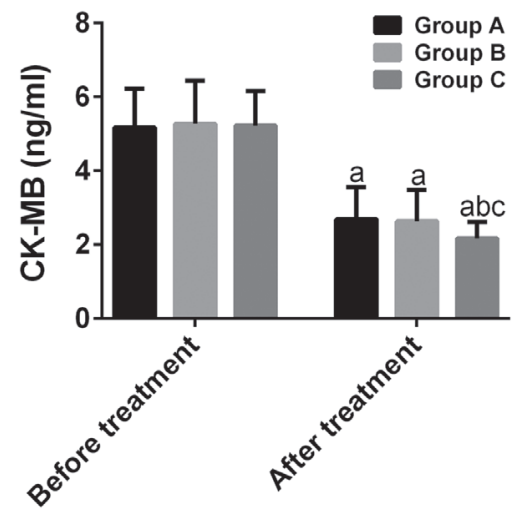

Figure 5. Comparison of CK-MB before and after treatment. Before treatment, there was no significant difference among groups $\mathrm{A}, \mathrm{B}$ and $\mathrm{C}$ in CK-MB. After treatment, there was no significant difference between groups $\mathrm{A}$ and $\mathrm{B}$, while in group $\mathrm{C}$ CK-MB was significantly lower than that in groups $\mathrm{A}$ and $\mathrm{B}$. After treatment, $\mathrm{CK}-\mathrm{MB}$ in the three groups was significantly lower than that before treatment. ${ }^{a} \mathrm{P}<0.001$, compared with $\mathrm{CK}-\mathrm{MB}$ in the same group before treatment; ${ }^{\mathrm{b}} \mathrm{P}<0.001$, compared with $\mathrm{CK}-\mathrm{MB}$ in group A after treatment; ${ }^{\mathrm{c}} \mathrm{P}<0.001$, compared with $\mathrm{CK}-\mathrm{MB}$ in group $\mathrm{B}$ after treatment. CK-MB, creatine kinase-MB.

score $(\mathrm{P}<0.001)$. After treatment, there was no significant difference between groups A and B in APACHE II score ( $P>0.050)$, while in group $C$ the score was significantly lower than that in groups $\mathrm{A}$ and $\mathrm{B}(\mathrm{P}<0.001)$. The wake-up time in group A was significantly longer than that in groups $B$ and $C$ $(\mathrm{P}<0.001)$, and the time in group $\mathrm{B}$ was longer than that in group $\mathrm{C}(\mathrm{P}<0.001)$ (Table III).

Comparison of adverse reactions. The incidence of adverse reactions was $3.95 \%$ in group A, $4.79 \%$ in group B and $3.82 \%$ in group $\mathrm{C}$, without a statistically significant difference among the three groups $(\mathrm{P}>0.050)$ (Table IV).

\section{Discussion}

Sepsis is an extremely common malignant disease, which poses a great threat to the life of ICU patients (17). Its main pathogenesis is infection-induced severe systemic inflammatory response, which usually causes multiple organ damage and failure (18). Sepsis complicated with myocardial damage is very common due to the extremely significant effects of toxins rich in septic bacteria and inflammatory mediators induced 
Table III. Comparison of sedative effects.

\begin{tabular}{lccrrr}
\hline Variable & Group A (n=152) & Group B (n=146) & Group C (n=131) & F value & P-value \\
\hline APACHE II before treatment & $18.67 \pm 4.26$ & $19.02 \pm 4.63$ & $18.87 \pm 4.30$ & 0.237 & 0.789 \\
APACHE II after treatment & $14.82 \pm 2.05$ & $14.63 \pm 2.28$ & $11.67 \pm 1.69^{\mathrm{a}, \mathrm{b}}$ & 103.324 & $<0.001$ \\
Wake-up time (min) & $120.37 \pm 28.15$ & $98.75 \pm 21.39^{\mathrm{c}}$ & $71.57 \pm 22.36^{\mathrm{c}, \mathrm{d}}$ & 142.308 & $<0.001$ \\
Length of ICU stay (days) & $7.82 \pm 3.25$ & $7.93 \pm 3.52$ & $7.75 \pm 3.35$ & 0.101 & 0.904 \\
\hline
\end{tabular}

${ }^{\mathrm{a}} \mathrm{P}<0.001$, compared with APACHE II score in group A after treatment; ${ }^{\mathrm{b}} \mathrm{P}<0.001$, compared with APACHE II score in group B after treatment; ${ }^{\mathrm{c}} \mathrm{P}<0.001$, compared with wake-up time in group $\mathrm{A} ;{ }^{\mathrm{d}} \mathrm{P}<0.001$, compared with wake-up time in group $\mathrm{B}$. ICU, intensive care unit.

Table IV. Comparison of adverse reactions [n (\%)].

\begin{tabular}{|c|c|c|c|c|c|}
\hline Adverse reaction & Group A $(\mathrm{n}=152)$ & Group B $(n=146)$ & Group C (n=131) & $\chi^{2}$ value & P-value \\
\hline Heat & $2(1.32)$ & $3(2.05)$ & $2(1.53)$ & & \\
\hline Chill & $0(0.00)$ & $1(0.68)$ & $2(1.53)$ & & \\
\hline Fast heart rate & $2(1.32)$ & $2(1.37)$ & $1(0.76)$ & & \\
\hline Nausea and vomiting & $2(1.32)$ & $1(0.68)$ & $0(0.00)$ & & \\
\hline Total incidence (\%) & 3.95 & 4.79 & 3.82 & 0.200 & 0.905 \\
\hline
\end{tabular}

by the bacteria on myocardial cells (19). Sepsis bacteria can cause mitochondrial structure damage, mitochondrial calcium overload and oxygen-free radical damage of myocardial cells, which may cause decline of the cardiac function, vascular endothelial damage and blood flow reduction in the early stages of the disease (20). Therefore, it is essential to evaluate the influence on cardiac function in the sedative treatment of sepsis. Propofol, midazolam and dexmedetomidine, as clinically common anesthetics, are widely used in surgical anesthesia and important for the sedative treatment of sepsis. Their therapeutic values have been recognized, but their differences in the sedative treatment of sepsis remain unclear. A study by Abdelmalik and Rakocevic has shown that propofol is a protective factor for septic respiratory failure (21), and the study of Zamani et al has revealed that dexmedetomidine can improve the survival time of ICU patients with sepsis (22). However, there are few comparative studies among the three drugs. The present study explored the most suitable drug for the sedative treatment of ICU patients with sepsis through rigorous inclusion and exclusion criteria and in-depth comparison of observation indexes, and therefore it is of clinical significance. In the present study, there was no significant difference among groups $\mathrm{A}, \mathrm{B}$ and $\mathrm{C}$ in HR, SBP, DBP, $\mathrm{PaO}_{2}, \mathrm{PaCO}_{2}$, cTnT, CK-MB, and APACHE II score before treatment, and in DBP, SBP, HR, cTnT, and length of ICU stay after treatment. After treatment, there was no significant difference between groups A and B in APACHE II score. APACHE II score in group C was significantly lower than that in groups A and B. In the three groups, the indexes after treatment were significantly better than those before treatment. These findings suggest that propofol, midazolam and dexmedetomidine are effective and safe for the sedative treatment of ICU patients with sepsis, but dexmedetomidine has the best effect. This is similar to the findings of Chen et al (23) and Sonneville et al (24), both of which support the results of this study. There was no difference in HR among the three groups, suggesting that the three sedation methods had the same effect on patients' cardiac function. As an $\alpha 2$ adrenergic receptor agonist that mainly acts on the $\alpha 2$ receptor in the locus nucleus ceruleus of brainstem, dexmedetomidine has sedative and analgesic effects on the nerve activity and an inhibitory effect on the sympathetic nerve through activating the $\alpha 2$ receptor (25). Sepsis damages the myocardial cells mainly through mitochondria. Therefore, the mechanism of action of dexmedetomidine may be that the activation of adrenergic pathways through the $\alpha 2$ receptor, accelerates the metabolism and production of glucose in the body, and then supplements and reconstructs damaged mitochondria in time, thereby relieving patients' pain and anxiety and protecting the myocardial function. Propofol plays the role of analgesia mainly through inhibiting the hypothalamus-pituitary-adrenal axis and reducing cortisol secretion (26).

Cortisol is closely related to the human perception and immune function. According to a study, cortisol binds to the surface receptors of immune cells and blocks the downstream signal transduction, causing the secretion and metabolism of inflammatory cytokines (27). Therefore, the protective effect of propofol on myocardial function may be related to the inhibition of cortisol. The inhibition of cortisol secretion reduces the activity of inflammatory cytokines, and other mechanisms of action do not arise through mitochondria, so the protective effect of propofol on patients with sepsis is less significant than that of dexmedetomidine. This is also the reason for the differences in the present study. Midazolam has typical pharmacological activity of benzodiazepine and anxiolytic, sedative, hypnotic, anticonvulsant and muscle relaxing effects, with a very high plasma protein binding rate. It is mainly metabolized by binding to glucose and then excreted by the kidney in the human body (28). The liver and kidney functions 
of ICU patients are more likely to be inferior to those of other patients, so the effect of midazolam on the ICU patients may be poorer. Therefore, midazolam is not suitable for the sedative treatment of ICU patients with sepsis. The results of this study revealed that the myocardial function of patients in group $\mathrm{B}$ are poorer than that in group $\mathrm{C}$, which has been confirmed. There was no significant difference among groups $\mathrm{A}, \mathrm{B}$ and $\mathrm{C}$ in the incidence of adverse reactions, which indicated that propofol, midazolam and dexmedetomidine are safe and feasible for the sedative treatment of sepsis.

This study compared the values of propofol, midazolam and dexmedetomidine in the sedative treatment of ICU patients with sepsis. However, the exact mechanisms of action of the three drugs were not verified due to limited experimental conditions. Therefore, further exploration is needed. Also, although there are various ICU patients, only a few ICU patients with sepsis were included in this study, so there may be differences with other types of patients.

In summary, propofol, midazolam and dexmedetomidine are effective and safe in the sedative treatment of ICU patients with sepsis, but dexmedetomidine has the best effect on protecting the blood pressure and cardiac functions, which is worthy of promotion.

\section{Acknowledgements}

Not applicable.

\section{Funding}

No funding was received.

\section{Availability of data and materials}

The datasets used and/or analyzed during the present study are available from the corresponding author on reasonable request.

\section{Authors' contributions}

JD and YC conceived and designed the study. YG acquired the patients' data. JD and YC analyzed and interpreted the data. JD was a major contributor in writing the manuscript. YG reviewed the manuscript. All authors read and approved the final manuscript.

\section{Ethics approval and consent to participate}

The study was approved by the Ethics Committee of Renji Hospital, School of Medicine, Shanghai Jiaotong University (Shanghai, China). Patients who participated in this research had complete clinical data. Signed informed consents were obtained from the patients or their guardians.

\section{Patient consent for publication}

Not applicable.

\section{Competing interests}

The authors declare that they have no competing interests.

\section{References}

1. Singer M, Deutschman CS, Seymour CW, Shankar-Hari M, Annane D, Bauer M, Bellomo R, Bernard GR, Chiche JD, Coopersmith $\mathrm{CM}$, et al: The third international consensus definitions for sepsis and septic shock (Sepsis-3). JAMA 315: 801-810, 2016.

2. Fleischmann C, Scherag A, Adhikari NK, Hartog CS, Tsaganos T, Schlattmann P, Angus DC and Reinhart K; International Forum of Acute Care Trialists: International Forum of Acute Care Trialists: Assessment of global incidence and mortality of hospital-treated sepsis. Current estimates and limitations. Am J Respir Crit Care Med 193: 259-272, 2016.

3. Fleischmann C, Thomas-Rueddel DO, Hartmann M, Hartog CS, Welte T, Heublein S, Dennler U and Reinhart K: Hospital incidence and mortality rates of sepsis: An analysis of hospital episode (DRG) statistics in Germany from 2007 to 2013. Dtsch Arztebl Int 113: 159-166, 2016.

4. Rhee C, Dantes R, Epstein L, Murphy DJ, Seymour CW, Iwashyna TJ, Kadri SS, Angus DC, Danner RL, Fiore AE, et al; CDC Prevention Epicenter Program: Incidence and trends of sepsis in US hospitals using clinical vs claims data, 2009-2014. JAMA 318: 1241-1249, 2017.

5. Polat G, Ugan RA, Cadirci E and Halici Z: Sepsis and septic shock: Current treatment strategies and new approaches. Eurasian J Med 49: 53-58, 2017.

6. Kadri SS, Rhee C, Strich JR, Morales MK, Hohmann S, Menchaca J, Suffredini AF, Danner RL and Klompas M: Estimating ten-year trends in septic shock incidence and mortality in United States Academic Medical Centers using clinical data. Chest 151: 278-285, 2017.

7. Marik PE, Khangoora V, Rivera R, Hooper MH and Catravas J: Hydrocortisone, vitamin $\mathrm{C}$, and thiamine for the treatment of severe sepsis and septic shock: A retrospective before-after study. Chest 151: 1229-1238, 2017.

8. Stoller J, Halpin L, Weis M, Aplin B, Qu W, Georgescu C and Nazzal M: Epidemiology of severe sepsis: 2008-2012. J Crit Care 31: 58-62, 2016.

9. Anderson BJ, Reilly JP, Shashaty MGS, Palakshappa JA, Wysoczanski A, Dunn TG, Kazi A, Tommasini A, Mikkelsen ME, Schweickert WD, et al: Admission plasma levels of the neuronal injury marker neuron-specific enolase are associated with mortality and delirium in sepsis. J Crit Care 36: 18-23, 2016.

10. Steingrub JS, Lagu T, Rothberg MB, Nathanson BH, Raghunathan K and Lindenauer PK: Treatment with neuromuscular blocking agents and the risk of in-hospital mortality among mechanically ventilated patients with severe sepsis. Crit Care Med 42: 90-96, 2014.

11. Marler J, Mohrien K, Kimmons LA, Vandigo JE, Oliphant CS, Boucher AN and Jones GM: Effects of propofol on vasopressor use in patients with sepsis and severe sepsis: A pilot study. J Crit Care 35: 155-160, 2016.

12. Kawazoe Y, Miyamoto K, Morimoto T, Yamamoto T, Fuke A, Hashimoto A, Koami H, Beppu S, Katayama Y, Itoh M, et al; Dexmedetomidine for Sepsis in Intensive Care Unit Randomized Evaluation (DESIRE) Trial Investigators: Effect of dexmedetomidine on mortality and ventilator-free days in patients requiring mechanical ventilation with sepsis: A randomized clinical trial. JAMA 317: 1321-1328, 2017.

13. Fernando SM, Rochwerg B and Seely AJE: Clinical implications of the Third International Consensus Definitions for Sepsis and Septic Shock (Sepsis-3). CMAJ 190: E1058-E1059, 2018.

14. Yamamura H, Kawazoe Y and Morimoto T: Dexmedetomidine in patients with sepsis requiring mechanical ventilation-reply. JAMA 318: 480-480, 2017.

15. Seymour CW, Liu VX, Iwashyna TJ, Brunkhorst FM, Rea TD, Scherag A, Rubenfeld G, Kahn JM, Shankar-Hari M, Singer M, et al: Assessment of clinical criteria for sepsis: For the Third International Consensus Definitions for Sepsis and Septic Shock (Sepsis-3). JAMA 315: 762-774, 2016.

16. Godinjak A, Iglica A, Rama A, Tančica I, Jusufović S, Ajanović A and Kukuljac A: Predictive value of SAPS II and APACHE II scoring systems for patient outcome in a medical intensive care unit. Acta Med Acad 45: 97-103, 2016.

17. van Vught LA, Klein Klouwenberg PM, Spitoni C, Scicluna BP Wiewel MA, Horn J, Schultz MJ, Nürnberg P, Bonten MJ, Cremer OL, et al; MARS Consortium: Incidence, risk factors, and attributable mortality of secondary infections in the intensive care unit after admission for sepsis. JAMA 315: 1469-1479, 2016. 
18. Braun D: A retrospective review of the sepsis definition after publication of sepsis-3. Am J Med 132: 382-384, 2019.

19. Kim KS, Suh GJ, Kim K, Kwon WY, Shin J, Jo YH, Lee JH and Lee H: Quick Sepsis-related Organ Failure Assessment score is not sensitive enough to predict 28-day mortality in emergency department patients with sepsis: A retrospective review. Clin Exp Emerg Med 6: 77-83, 2019.

20. Vaez H, Rameshrad M, Najafi M, Barar J, Barzegari A and Garjani A: Cardioprotective effect of metformin in lipopolysaccharide-induced sepsis via suppression of toll-like receptor 4 (TLR4) in heart. Eur J Pharmacol 772: 115-123, 2016.

21. Abdelmalik PA and Rakocevic G: Propofol as a risk factor for ICU-acquired weakness in septic patients with acute respiratory failure. Can J Neurol Sci 44: 295-303, 2017.

22. Zamani MM, Keshavarz-Fathi M, Fakhri-Bafghi MS, HirbodMobarakeh A, Rezaei N, Bahrami A and Nader ND: Survival benefits of dexmedetomidine used for sedating septic patients in intensive care setting: A systematic review. J Crit Care 32: 93-100, 2016

23. Chen Y, Zhang X, Zhang B, He G, Zhou L and Xie Y: Dexmedetomidine reduces the neuronal apoptosis related to cardiopulmonary bypass by inhibiting activation of the JAK2-STAT3 pathway. Drug Des Devel Ther 11: 2787-2799, 2017.

24. Sonneville R, de Montmollin E, Poujade J, Garrouste-Orgeas M, Souweine B, Darmon M, Mariotte E, Argaud L, Barbier F, Goldgran-Toledano D, et al: Potentially modifiable factors contributing to sepsis-associated encephalopathy. Intensive Care Med 43: 1075-1084, 2017.
25. Ren X, Ma H and Zuo Z: Dexmedetomidine postconditioning reduces brain injury after brain hypoxia-ischemia in neonatal rats. J Neuroimmune Pharmacol 11: 238-247, 2016.

26. Barnes J, Hunter J, Harris S, Shankar-Hari M, Diouf E, Jammer I, Kalkman C, Klein AA, Corcoran T, Dieleman S, et al; StEPCOMPAC group: Systematic review and consensus definitions for the Standardised Endpoints in Perioperative Medicine (StEP) initiative: Infection and sepsis. Br J Anaesth 122: 500-508, 2019.

27. McGregor BA, Murphy KM, Albano DL and Ceballos RM: Stress, cortisol, and B lymphocytes: A novel approach to understanding academic stress and immune function. Stress 19: 185-191, 2016.

28. Shankar-Hari M, Phillips GS, Levy ML, Seymour CW, Liu VX, Deutschman CS, Angus DC, Rubenfeld GD and Singer M; Sepsis Definitions Task Force: Developing a new definition and assessing new clinical criteria for septic shock: For the Third International Consensus Definitions for Sepsis and Septic Shock (Sepsis-3). JAMA 315: 775-787, 2016.

This work is licensed under a Creative Commons Attribution-NonCommercial-NoDerivatives 4.0 International (CC BY-NC-ND 4.0) License. 